\title{
GESTÃO DEMOCRÁTICA E O PROCESSO DE EDUCAÇÃO INCLUSIVA: UMA RELAÇÃO POSSÍVEL?
}

Rosana Carla Gonçalves Gomes Cintra ${ }^{(*)}$

\section{INTRODUÇÃO}

No atual cenário de políticas nacionais vivenciamos um importante momento histórico com a crescente oficialização dos princípios da educação com documentos e diretrizes que preconizam a educação como direito de todos. Em 1988 com a implementação da Constituição Federal e em 1996 com a nova Lei de Diretrizes e Bases da Educação Nacional. A educação brasileira passa a tomar novos rumos - o da democratização do acesso ao ensino de qualidade para todos.

O presente artigo busca a partir das indagações no campo da Educação Especial na perspectiva da inclusão analisar a relação da Gestão Democrática e da Educação Inclusiva, tecendo a seguinte problemática: é possível uma educação inclusiva tendo como pressuposto uma gestão escolar que se constitui democrática? A fim de encontrarmos respostas na análise que se segue, optamos por abordagem qualitativa tendo como referencial teórico as contribuições de Lev Semionovich Vigotski (1989; 1991; 1998), com a Teoria Histórico-Cultural. A fim de fundamentar a discussão no campo da Gestão Democrática trazemos as contribuições de Vitor Henrique Paro (1994; 2001), teórico que possibilita uma abordagem crítica.

\section{OFICIALIZAÇÃO DO DIREITO A EDUCAÇÃO: DA EDUCAÇÃO INCLUSIVA A GESTÃO DEMOCRÁTICA}

Trazemos como hipótese de que há um distanciamento entre a oficialização do direito a educação e a sua implementação, o contexto real de aplicação das políticas públicas oficializadas.

Os princípios de direito a educação são garantidos e preconizados em lei, com forte movimento na década de 1990, época em que a educação começa a ganhar novos contornos e expressos em 1988 com a nova Constituição Federal. A Constituição Federal de 1988 é evocada

\footnotetext{
(*) Graduação em Pedagogia com habilitação em Administração Escolar, pela FUCMAT, atualmente, Universidade Católica Dom Bosco (1988); mestrado em Educação pela Universidade Católica Dom Bosco (1999) e doutorado em Comunicação e Semiótica pela Pontifícia Universidade Católica de São Paulo (PUC-SP)(2003). Atualmente é professora adjunto 3 da Universidade Federal de Mato Grosso do Sul (UFMS), Departamento de Educação (CCHS), Professora e Orientadora do Mestrado e Doutorado em Educação da UFMS, na Linha de Pesquisa Educação, Psicologia e Prática Docente e também do Programa de Mestrado em Educação Social da UFMS Campus do Pantanal em Corumbá, na Linha de Pesquisa Formação Docente e Diversidade.
} 
como documento que permite a nação brasileira tomar novos rumos em todas as esferas políticas, econômicas, sociais, educacionais, entre outras, e consolida a educação para todos. A educação para todos é posteriormente reafirmada no documento próprio da educação em 1996 com a nova LDB Lei de Diretrizes e Bases, Lei 9.394/1996.

A Constituição Federal de 1988 e a Lei 9.394/1996 estabelecem a educação como direito de todos e garantem o atendimento educacional especializado as pessoas com deficiência como atendimento preferencial na rede regular de ensino.

Observamos que os documentos oficiais ao tratar da inclusão trazem também como um dos seus objetivos a valorização da participação da sociedade em geral, tanto em formação de professores, participação da família e da comunidade escolar e de todos os setores, bem como a acessibilidade em todos os espaços sociais que permite a socialização das pessoas com deficiência. Numa defesa de que não basta apenas garantir a matrícula dos alunos com deficiência, é preciso garantir também a sua permanência, o acesso ao conhecimento, à aprendizagem e a participação.

No entanto a história da sociedade brasileira é marcada por uma gestão centralizadora, hierárquica em suas raízes, com privilégios de poucos à custa da população. Após um período de ditatura na década de 1960, a sociedade brasileira passa por reformas garantindo a redemocratização do país na década de 1990, resultado do movimento das lutas e conquistas sociais. Com esse movimento há uma retomada na organização da educação, com princípios de educação para todos.

A democracia é oficializada como princípio constitucional, o Estado Democrático de Direito é instaurado na democracia brasileira garantido em seu artigo $1^{\circ}$ na Constituição Federal de 1988. Nesse momento uma nova gestão é encetada, culminando na gestão democrática como um dos princípios da educação.

A população passa a ser aclamada com o objetivo de participação de todo nas decisões escolares apresentando uma nova configuração de gestão que pressupõe um poder descentralizado. No entanto esse movimento é configurado num sistema mais amplo, de sociedade capitalista, globalizada e consumista os conceitos de participação e democracia ligados à ideia de produtividade e competitividade, do ideal neoliberal, apontando os entraves para a concretização de uma gestão democrática.

Nesse processo que o debate sobre a gestão democrática e a perspectiva de uma educação inclusiva ganha destaque, na transformação da escola e da sociedade para a construção de uma 
educação inclusiva e democrática. Entendendo a escola como reprodutora das relações mais amplas, mas também produtora de novas relações.

\section{PRESSUPOSTOS METODOLÓGICOS}

Orientamos nossa metodologia por levantamento, seleção e análise bibliográfica das publicações divulgadas em acervos que possuem grande destaque para as pesquisas em educação no Brasil, a saber: Associação Nacional de Política e Administração da Educação (ANPAE); Biblioteca Digital de Teses e Dissertações (BDTD); Coordenação de Aperfeiçoamento de Pessoal de Nível Superior (CAPES); e Scientific Eletronic Library Online (SciELO ). Optamos por levantamento de dados a partir das palavras-chave: gestão democrática e educação inclusiva; e selecionamos os textos vinculados apenas à educação básica.

Nossos resultados apontaram um total de 21 trabalhos. Elencamos apenas oito, conforme a orientação de nossa pesquisa para leitura e análise, divulgados a partir do ano de 2005 até 2016.

A fim de conhecer e problematizar a realidade do processo de educação inclusiva, bem como as contribuições e implicações da gestão democrática nesse processo foi realizado uma pesquisa com os resultados do "Questionário para Professores de Educação Especial". Esse Questionário constitui-se um "Inquérito para professores do Brasil que atuam na educação da infância e possuem crianças inclusas"3. O questionário foi aplicado no período de Janeiro a Junho de 2016. Selecionamos e agrupamos as questões que encontrassem diretamente a discussão das temáticas - Educação Inclusiva e Gestão Democrática, para posterior análise das respostas. Dentre as 127 questões levantadas, foram selecionadas 59.

\section{DA EDUCAÇÃO INCLUSIVA A GESTÃO DEMOCRÁTICA - UM MAPEAMENTO TEÓRICO}

A análise investigativa partiu do pressuposto de que a relação estabelecida entre os grandes temas ainda é pouco discutida nas pesquisas educacionais. Apesar de grande influência nas pesquisas os temas Educação Inclusiva e Gestão Democrática separadamente. Tendo em vista a importância desses temas e a atual defesa nas Políticas Públicas de uma educação inclusiva e uma educação democrática buscamos elementos para compreender e discutir as contribuições e implicações da gestão democrática para a educação inclusiva. Se o processo de inclusão implica em tomada de atitudes e decisões, aqui a gestão democrática se torna imprescindível. 
A princípio os autores aparentam unanimidade quando tratam da importância de uma gestão democrática para a educação inclusiva, apesar de contextos diferentes de pesquisa conforme explicitados a seguir.

Autores como Costa (2013), Silva (2009), Silva e Leme (2006) dão destaque ao papel do gestor como articulador, mediador e mobilizador desse processo, apesar de compreenderem que o gestor não é único sujeito nesse processo, mas que o gestor tem papel preponderante na articulação das ações da escola. Menino-Mencia (2016), Silva (2006) e Silva e Leme (2009) avança no conceito de inclusão para uma cultura inclusiva na superação de uma cultura de exclusão.

A formação continuada como parte do processo de práticas e políticas inclusivas é defendida por todos os autores com a possibilidade de informação e de conhecimento por parte de toda equipe escolar. Uma formação continuada como suporte pedagógico a fim de "suprir a defasagem de conhecimentos sobre os temas relacionados à inclusão" (COSTA, 2013, p. 72). A constante reestruturação da proposta pedagógica na sociedade contemporânea requer uma contínua formação, "profissionais cada vez mais completos" (COSTA, 2013, p. 73). Com a possibilidade de a escola vivenciar uma gestão menos burocrática, mais participativa e democrática.

Portanto uma formação continuada como parte do discurso, no entanto quando a defesa de uma formação distante do projeto da escola, sem mudanças estruturais, pode levar a uma responsabilização incoerente de um grupo ou de uma pessoa pela inclusão (VIZIM, 2009).

Existe certa ressonância no que diz respeito à importância de envolver toda comunidade escolar a fim de compartilhar do ideal de inclusão, uma participação que não fica restrita a equipe escolar, profissionais da educação, mas envolve também os alunos (MENINO-MENCIA, 2016).

Há certa ressonância quanto à defesa de um projeto realizado na construção coletiva como estratégia para a política de inclusão e não a responsabilização de um único ator ou grupo, tampouco a centralização das decisões (SILVA, 2009). Recorrer à coletividade como estratégia de democratização do espaço escolar e da educação desenvolvendo um sentimento de pertencimento por parte de todos, capaz de transpor barreiras estruturais. O envolvimento de todos os atores na implementação da política de inclusão, requer um envolvimento não só na execução da política, como também o importante envolvimento na sua elaboração, isto é, construção coletiva de plano de ações contextualizadas a realidade escolar (COSTA, 2013). Não apenas efetivar a matrícula, mas desenvolver uma cultura inclusiva, isto é, “[...] pensar e planificar ações para que a escola desenvolva, no seu cotidiano, práticas inclusivas.” (MENINO-MENCIA, 2016, p. 21). 
Uma educação libertadora, com práticas emancipadoras não para um grupo específico, mas toda classe trabalhadora, pois no capitalismo todos são excluídos. Mesmo no contexto da contradição, a escola inclusiva tem na participação o caminho para a inclusão (VIZIM, 2009, p. 44).

\section{DA PESQUISA REALIZADA - UMA ANÁLISE DO QUESTIONÁRIO PARA PROFESSORES DE EDUCAÇÃO ESPECIAL}

Referente aos resultados da pesquisa "Questionário para Professores de Educação Especial" e para análise que nos interessa iniciamos com uma amostra de 21 professores, sendo dezesseis mulheres e quatro homens ${ }^{4}$, dezessete são educadores na rede pública, três na rede privada; treze atuando na escola, quatro em creche, três em pré-escola.

Nas questões referentes ao relacionamento dos professores/sujeitos da pesquisa com os profissionais/colegas de trabalho, crianças, pais, superiores hierárquicos e comunidade houve preponderância em todas as respostas que indicavam aspectos positivos e facilidade no relacionamento com todos os envolvidos, apesar de algumas nuances de respostas que indicam aspectos negativos e dificuldades no relacionamento com superiores hierárquicos.

Trazemos como importante também para discussão a questão referente ao sentimento de frustação no trabalho, 7 indicaram concordar com esse sentimento; apesar de que a maioria indicou gostar das relações que estabelecem no trabalho.

Referente às práticas e concepções sobre a educação inclusiva alguns responderam concordar que as crianças com deficiência aprendem mais lentamente: quatorze concordam. No entanto, apesar de a maioria indicar concordar que as crianças com deficiência aprendem mais lentamente, em outra questão proposta a maioria discorda que a criança com deficiência não aprende, incomoda e vai atrapalhar o trabalho em sala de aula (um concorda). E um concorda totalmente que as crianças com deficiência não podem ser incluídas no ensino regular. Dezenove concordam no direito a educação individualizada de acordo com as deficiências das crianças, um discorda. E doze indicaram que o preconceito do educador de infância sobre a inclusão das crianças com deficiência não interfere na prática em sala de aula.

Nos aspectos pessoais e de formação é interessante salientar que poucos frequentaram a disciplina referente à Educação Especial tanto em formação inicial como na continuada, no entanto os dados apontaram que a maioria conhece sobre os conceitos perguntados. Alguns sujeitos, embora o número não seja expressivo, têm dificuldade em informar, em praticar, em trabalhar de forma colaborativa quando o assunto é educação inclusiva. 
Ainda referente à formação, ninguém frequentou a disciplina de Gestão/Administração da sala de aula, mas o questionário indica que 30\% e 60\% frequentaram a disciplina de Educação Especial / Dificuldades de Aprendizagem tanto em formação inicial (seis pessoas) e como na formação continuada (doze pessoas), respectivamente.

É perceptível o quanto é pouco debatido os conceitos sobre a educação inclusiva, gerando discordância entre as respostas de uma questão e outra, semelhantes entre si. A escola ainda não dá conta da multiplicidade de sujeitos na sua diversidade. Encontra-se também dificuldades na relação dos professores com seus superiores e a gestão da escola, desfavorecendo práticas e concepções mais democráticas, o professor acaba ficando com o papel apenas de executor, fragmentado no seu trabalho. Questões que serão debatidas no item a seguir.

\section{IMPLICAÇÕES E CONTRIBUIÇÕES DA GESTÃO DEMOCRÁTICA PARA A EDUCAÇÃO INCLUSIVA}

Para finalização do artigo buscamos na bibliografia consultada o olhar crítico dos textos de Vitor Henrique Paro para fundamentar nossa concepção sobre gestão democrática. Uma preocupação central se evidencia, a saber: os princípios democráticos e inclusivos se fazem importantes quando tem em vista uma educação emancipadora dos sujeitos, "a fim de expormos as contradições concretas existentes e viabilizarmos o processo de democratização." (PARO, 2001, p. 9).

É na Teoria Histórico-cultural de Vigotski que encontramos as bases necessárias aos objetivos a que nos propomos apreender os significados, significações e conceitos socialmente elaborados acerca da educação inclusiva como fenômeno histórico e social, o processo de construção da subjetividade dos sujeitos. Essa análise possibilita captar as relações sociais historicamente, mais amplas em sua totalidade e contradições, compreender o homem e o modo como produz suas relações materiais.

Lev S. Vigotski é considerado precursor da educação inclusiva, pois fornece uma base teórica para a concepção de educação inclusiva revolucionária na sua época, de que a criança deficiente “[...] não é simplesmente menos desenvolvida que seus coetâneos normais, e sim desenvolvida de um outro modo.” (1929, p. 12). Tecendo severas críticas para o sistema de ensino fechado para (1989), pois o desenvolvimento da criança com necessidades especiais se faz necessário na interação social, esta não é diferente dos outros sujeitos qualitativamente, os significados culturais são os mesmos, o que diferencia é a forma de acesso e a sua apropriação, o que torna singular o seu desenvolvimento cultural (VIGOTSKI, 1989, p. 18). 
Um uníssono debate sobre a educação inclusiva e a gestão democrática aponta o papel de um educador ou um grupo de educadores como papel preponderante na promoção de uma escola inclusiva, seja ele diretor/diretor-adjunto/gestor ou professor/professores. O educador como articulador, mediador é concomitante ao ideal de educador, organizador do meio, proposto por Vigotski. Essa mediação como oportunidades e possibilidades, abertura de espaços e promoção do conhecimento e informação.

Essa concepção permite pensar na cultura inclusiva, enquanto valores apropriados, valores que são construídos socialmente e de que o indivíduo se apropria, no entanto tem-se a capacidade de modificar esses valores: "[...] nas formas superiores do comportamento humano, o indivíduo modifica ativamente a situação estimuladora como uma parte do processo de resposta a ela." (VIGOTSKI, 1991, p. 42). Um processo de inter-relação e colaboração com o meio. Uma relação de mediação em que pressupõe que as relações sociais não são menos e nem mais importantes que a ação criativa do sujeito.

Com os fundamentos da "defectologia" Vigotski ultrapassa os conceitos tradicionais baseados nas limitações da deficiência, apologia na falta no indivíduo, seu caráter biologizante de que a criança é menos desenvolvida. Para a superação desse conceito Vigotski propõe um conceito revolucionário na sua época e até os dias atuais, de que o sujeito com defeito é desenvolvido de um outro modo, uma visão das especificidades de cada sujeito, concepção qualitativa do sujeito diferente, que foca nas suas possibilidades, visão que contrapõe a visão das limitações, da falta. Pois “[...] a criança, cujo desenvolvimento se tem complicado por um defeito, não é essencialmente menos desenvolvida que seus coetâneos normais, é uma criança, porém desenvolvida de outro modo" (VIGOTSKI, 1989, p. 3).

A sociedade que constrói as limitações biológicas segrega, exclui, limita, coloca no sujeito a culpa pelas mazelas sociais, mas é preciso transpor essas barreiras para a construção da sociedade da diversidade, a construção do conhecimento na coletividade capaz de desenvolver as potencialidades dos sujeitos plenamente. Mas não se pode negar a tentativa de adaptação do sujeito ao currículo, apesar da crescente demanda política de incentivo a adaptação do currículo, prática de difícil concretização, devido às precárias condições estruturais para transformação do currículo, é preciso pensar em currículo crítico, criativo, capaz de oportunizar experiências democráticas.

Perceber a escola que é na sua realidade e que as concepções atuais e difundidas parecem ocultar (PARO, 2001, p. 10). Por isso a construção de espaço de reuniões e encontros para debates e discussões na escola se faz pertinente de modo que a escola não seja simples executora de normas, 
mas que seja possível a construção de um espaço coletivo onde essas normas possam ser discutidas, onde encontros para estudos possam ser realizados, sem isentar a função social do Estado.

\section{CONSIDERAÇÕES FINAIS}

Entendemos a educação inclusiva e a gestão democrática como processos e em constantes modificações, quando o objetivo da coletividade não é atingido, é preciso reconstruir o debate, redirecionando as práticas sociais e educacionais.

A escola na sua função social é defendida no atual cenário como espaço propício para a formação, consciência crítica e construção coletiva de um projeto político na busca de uma educação emancipadora. No entanto percebemos como essa defesa não pode desassociar de uma visão mais ampla, que limita as condições estruturais da escola para a transformação da educação, em uma educação de qualidade para todos, levando a um círculo vicioso em um crescente discurso de responsabilização dos seus atores.

Nossos resultados apontaram a dificuldade do trabalho com a multiplicidade de sujeitos, bem como o desfavorecimento de práticas e concepções mais democráticas, quando tem em vista a fragmentação do trabalho do professor, com papel apenas de executor das normas estabelecidas. Por isso a importância conjunta da formação e pesquisa como parte do processo de construção de uma escola mais inclusiva e democrática, possibilidades de formar sujeitos conscientes e críticos, capazes de compreender os interesses nos discursos desde as suas origens e fomentar novos debates. 


\section{REFERÊNCIAS}

BAGGIO, S.S.R. A implementação da educação inclusiva em uma escola no município de Cristalina - GO. 95 f. Dissertação (Mestrado Profissional) - Escola Superior de Teologia, São Leopoldo, 2010. Disponível em: <http://tede.est.edu.br/tede/tde_busca/arquivo.php?codArquivo=255> Acesso em: 07 jul. 2016.

BRASIL. Constituição da República Federativa do Brasil: Texto constitucional promulgado em 5 de outubro de 1988, com as alterações adotadas pelas Emendas Constitucionais 1/92 a 67/2010, pelo Decreto 186/2008 e pelas Emendas Constitucionais de Revisão1 a 6/94. Diário Oficial da União. Brasília: 1988. 578 p.

Lei de Diretrizes e Bases. Lei 9.394 de 20 de dezembro de 1996. Estabelece as diretrizes e bases da educação nacional. Diário Oficial da União. Brasília: 18 abr. 1997.

2007.

Política Nacional de Educação Especial na Perspectiva da Educação Inclusiva. Brasília: MEC/SEESP,

COSTA, H.L A implementação da política de inclusão no município de Quissamã/RJ - uma análise comparativa entre $1^{\circ}$ e $2^{\circ}$ segmento do ensino fundamental. 97 f. Dissertação (Mestrado Profissional) - Faculdade de Educação, Universidade Federal de Juiz de Fora, Juiz de Fora, 2013. Disponível em: <http://bdtd.ibict.br/vufind/ Record/UFJF_2a0a12eac598c6c78ff06fe 757ddf432>. Acesso em: 05 jul. 2016.

DUTRA, C.P.; GRIBOSKI, C.M. Gestão para inclusão. Disponível em: <http://periodicos.ufsm.br/educacaoespecial/ article/view/4372/2566>. Acesso em: 29 jul. 2016.

HORA, D. L. Os sistemas educacionais municipais e a prática de gestão democrática: novas possibilidades de concretização. Disponível em: <http://rieoei.org/1669.htm〉. Acesso em: 25 jul. 2016.

MENINO-MENCIA, G.F. Processos de inclusão e exclusão escolar: um estudo em uma escola pública do ensino fundamental I utilizando o "Index para Inclusão". 156 f. Dissertação (Mestrado em Ciências) - Faculdade de Ciências Bauru, Universidade Estadual Paulista, 2016. Disponível em: <http://bdtd.ibict.br/vufind/Record/UNSP_676092a7c 432d40cd7a7f87062e6131f>. Acesso em: 04 jul. 2016.

PARO, V.H.. Gestão da Escola Pública: Alguns Fundamentos. [S.l.: s.n., s/d]. Disponível em: <http://rbep.inep .gov.br/index.php/rbep/article/view/1177/1151>. Acesso em: 15 jul. 2016.

Gestão democrática da escola pública. São Paulo: Ática, 2001.

SILVA, C. L. O papel do diretor escolar na implantação de uma cultura educacional inclusiva a partir de um enfoque sócio-histórico. 143 f. Dissertação (Mestrado em Psicologia) - Instituto de Psicologia da Universidade de São Paulo, São Paulo, 2006. Disponível em: <http://www.teses.usp.br/teses/disponiveis/47/47131/tde-22052007-150941/ptbr.php>. Acesso em: 19 jul. 2016.

; LEME, M.I.S. O papel do diretor escolar na implantação de uma cultura educacional inclusiva. [S.l.: s.n., s/d]. Disponível em: <http://www.scielo.br/scielo.php?script=sci_arttext\&pid=S1414-9893200900 0300006\&lang=pt $>$. Acesso em: 19 jul. 2016.

VIGOTSKI, L. S. Formação social da mente. 4 ed. São Paulo: Martins Fontes, 1991.

Pensamento e Linguagem. Rio de Janeiro: Martins Fontes, 1998.

Psicologia pedagógica. Porto Alegre: Artmed, 2003.

VIZIM, M. Avanços e impasses nas políticas públicas de inclusão: o centro de atenção à inclusão social de Diadema. [S.1.: s.n., s/d]. Disponível em: 〈http://www.teses.usp.br/teses/disponiveis/48/48134/tde-24092009-161637/pt-br.php>. Acesso em: 07 jul. 2016. 


\section{RESUMO}

O artigo é recorte da pesquisa que tem como investigação a relação da gestão democrática no processo de educação inclusiva. Discutimos no campo da Educação Especial na perspectiva da inclusão tecendo a seguinte problemática: qual a relação da gestão democrática no processo de educação inclusiva? Os procedimentos metodológicos foram pesquisas em bancos de dissertações e teses no Brasil e análise do questionário intitulado "Inquérito para professores do Brasil que atuam na educação da infância e possuem crianças inclusas". Como resultados, a dificuldade do trabalho escolar com a multiplicidade de sujeitos, dificuldades nas práticas e concepções democráticas, tendo em vista a fragmentação do trabalho do professor.

Palavras-chave: Educação Especial. Inclusão. Gestão Democrática.

\section{DEMOCRATIC MANAGEMENT AND THE INCLUSIVE EDUCATION PROCESS: A POSSIBLE RELATIONSHIP?}

\section{ABSTRACT}

This paper is to research the relationship of democratic management in inclusive education process using as theoretical basis the contributions of Vygotsky with the Theory Historical-Cultural. We start the discussions in the field of special education in the perspective of inclusion weaving the following issues: what is the relationship of democratic management in the inclusive education process? To find answers, we organize our methodological procedures for research in great influence proceedings in Brazil and analysis of the survey entitled "Survey for Brazil of teachers who work in child education and have included children." As a result, we show the difficulty of school work with the multiplicity of subjects, and the disadvantage of more democratic practices and concepts, when you have in mind the fragmentation of teacher's work. We live in the present scenario of national policies increasing formalization of the principles of education as an important historical moment with the implementation of the Constitution of 1988 and in 1996 with the new Law of Guidelines and Bases. Brazilian education takes new directions, the democratization of access to quality education for all; however one cannot fail to grasp the discourses associated with this defense, as a result of the broader relations.

Keywords: Special Education from the perspective of inclusion. Inclusive Education Process. Democratic Management.

\section{GESTIÓN DEMOCRÁTICA Y EL PROCESO DE EDUCACIÓN INCLUSIVA: UNA RELACIÓN POSIBLE?}

\section{RESUMEN}

El artículo es recorte de la investigación que tiene como investigación la relación de la gestión democrática en el proceso de educación inclusiva. Discutimos en el campo de la Educación Especial en la perspectiva de la inclusión tejiendo la siguiente problemática: ¿cuál es la relación de la gestión democrát ica en el proceso de educación inclusiva? Los procedimientos metodológicos fueron investigaciones en bancos de disertaciones y tesis en Brasil y análisis del cuestionario titulado "Encuesta para profesores de Brasil que actúan en la educación de la infancia y poseen niños incluidos". Como resultados, la dificultad del trabajo escolar con la multiplicidad de sujetos, dificultades en las prácticas y concepciones democráticas, teniendo en vista la fragmentación del trabajo del profesor.

Palabras clave: Educación Especial. Inclusión. Gestión Democrática.

Submetido em: 20 de setembro de 2018 Aprovado em: 30 de abril de 2019 